\title{
Some psychological aspects of distant teaching
}

\author{
G.P. Grigoriev ${ }^{1 *}$, and A.A. Beresnev ${ }^{2}$ \\ ${ }^{1}$ V.I. Vernadsky Crimean Federal University, Simferopol, Russia \\ ${ }^{2}$ V.I. Vernadsky Crimean Federal University, Simferopol, Russia
}

\begin{abstract}
The article presents a short review of works dealing with distant teaching problems and the results of students and lecturers' survey at a higher educational institution about their attitude to distant teaching and psychological problems arising in the process of implementation. The experiment conducted reveals the major part of students and lecturers' positive attitude towards the form of distant teaching which is being applied at the present period of time. As the main drawback of distance teaching, the surveyed students pointed out the lack of direct contact with a lecturer ( $45 \%$ of students who rated distance education in a negative way). The revealed important negative aspect of distance teaching is that some students began to spend more time getting ready for classes (21\%). $55 \%$ of lectures are positive about distance education, and $45 \%$ are neutral. There are no people who rated in a negative way or very positive. Among those who gave a positive estimation of distance teaching, $33 \%$ of respondents, as well as students, indicate a high structure of educational material. Those lecturers, who have a satisfactory degree of distance teaching skills, but indicate that this work requires a lot of effort, turned out to be $90 \%$.
\end{abstract}

\section{Introduction}

Information technologies are being persistently introduced into the educational process, which is traditionally carried out by transmitting information directly from the lecturer to the student "face to face". This implementation was especially rapid and abrupt during the Covid-19 pandemic, when all secondary schools and higher educational institutions in the Russian Federation were quarantined and had to reorganize the educational process in a distant form, taking into account the experience of leading universities and schools already accumulated by that time.

Therefore, the problem of the self-concept as a factor of the professional identity of future psychologists at the stage of acquiring a profession requires special study.

\section{Research questions}

Experience demonstrates that teaching using information technologies has clear advantages over traditional methods. N. Alexandrova describes these advantages in the following way [1]:

${ }^{*}$ Corresponding author: geogrig@,rambler.ru 
1. Flexibility - students conduct their learning activities at a convenient time, place, and tempo.

2. Modularity - the modular principle is the basis of the curricula for distant teaching. Each individual curriculum is adequate to the content of a particular subject area.

3. Parallelism - teaching can take place with professional activities simultaneously;

4. An action at a distance - distance availability between a student and an educational institution is not an obstacle to an effective educational process;

5. Asynchronous - a student and a lecturer work in a convenient mode for each of them;

6. Mass - the number of students is not a critical parameter;

7. Profitability - profitability is characterized by economic efficiency;

8. New information technologies - new technological means of information transmission are mainly used: computer networks, multimedia systems, etc.

9. Sociality - availability of equal opportunities for education irrespective of the residence place and social status of students;

10. Internationality - internationality makes the transmission of educational services across national borders easy.

T. Kolderie and T. McDonald [2] note that "the main feature of ICT education (education with the use of information technologies) is that it may allow to take a student's interests, needs, strengths and weaknesses into account to conduct the teaching process with an instructor who makes this process easier without dictating to the student." At the same time, some researchers, T. V. Kuzmina [3], for instance, revealed some significant shortcomings of information technologies in teaching:

"1. Attempts to use old teaching methods with new technologies - most of the training materials elaborated for traditional training cannot be transferred into the online or mixed teaching system automatically.

2. Significant difficulties that lecturers can have when combining the natural human need for communication with ICT (information and computer technologies) - a lecturer has to make a lot of effort for his elaborated course to imitate live communication.

3. Educational problems dealing with the fact that a "remote student", learning only with ICT, does not have an opportunity to develop the necessary skills that he could develop at lectures and seminars (personal presentation techniques, "live" discussion and control of emotions, etc.)

4. There is still a lack of professionalism in the elaboration of training materials for ICT teaching. There is a need for special training of lecturers to work with new technologies, as not all lecturers can master new educational technologies, independently. Without special training, teachers elaborate courses of unsatisfactory quality.

A. Heinze and C. Procter [4] paid attention to some psychological features of mixed teaching. The authors note that, "mixed teaching is not just a combination of "face-to-face" teaching and online teaching. An essential point is the new elements of social interaction occurrence [6]. It is necessary that students should be given an opportunity to communicate $[7,8]$. Knowing each other makes communication easier and reduces the fear of posting your message in the forum. Communication between students and a lecturer plays an important role in creating an effective learning environment" $[9,10]$.

One of the problems of ICT education is that knowledge carriers are still mature experienced lecturers and professors who do not have theoretical training and practical skills in using the latest information technologies [11,12]. On the other hand, knowledge consumers are young people who have been used to communicating with a computer, tablet, and smartphone since childhood. At the same time, psychological barriers to communication inevitably arise $[13,14]$. 
The purpose of our research was to state the psychological and organizational problems arising during the rapid introduction of distance teaching.

128 students of different courses and specialties were interviewed. The question was "What is your attitude towards the distance teaching in its modern form?" The responses were distributed as follows:

Very positive $-22 \%$

Positive $-23 \%$,

Neutral $-30 \%$,

Negative $-22 \%$,

Very negative $-3 \%$

It is noteworthy that the majority of students in general have a positive attitude to distance teaching, in spite of the fact that suddenly they had to change the usual way of students' life with traditional ways of learning. However, there are not so few students who are negative about the innovation $(22 \%)$, in addition, there are those who are extremely negative about distance teaching (3\%).

For those who gave a positive estimation of distance teaching, follow-up questions were about specifying their positive attitude. Among the positive aspects, the majority of respondents noted that lecturers provide students with well-structured material in distance teaching $(28 \%)$. You may think that getting ready for a lecture or a practical class requires that a lecturer "clear" the educational material from unnecessary information, build it logically, accompanying with a good presentation. Students noted a high level of presentations made by lecturers (24\%).

Another important positive aspect of distance teaching is that a lecture may not be outlined. Its text is uploaded by a lecturer to the website. This point is indicated as positive by $24 \%$.

Unexpectedly, the essential point of distance teaching was that you can take your mind off the lecture for a while. This was indicated by $26 \%$ of respondents. In one of the questionnaires, it was stated as follows: "It provides an opportunity to combine education with work and taking care of a small child".

Among the positive reviews you can come across the following: "Saving time for both a lecturer and a student, no need to spend time on the road", "it takes less time, no need to go to the Institute, and lose another 2 hours on the road", "For me, as an already employed person, this type of training is a kind of "salvation". I can attend almost all classes".

The negative attitude to distance teaching was revealed in the process of clarifying questions in the questionnaire. As the main drawback of distance teaching, respondents indicated that there was no direct contact with a lecturer $(45 \%$ of those who rated distance education negatively). The number is to be paid special attention to. No matter what many experts say about the positive aspects of distance education, students highly appreciate direct communication with a lecturer.

The students' next remark is directly related to the previous one. They note that during an offline lecture, the lecturer casually gives a lot of important and interesting information (24\%). Apparently, the desire to structure the material, which is highly appreciated by some students, is negative for others.

The possibility of distracting from the lecture for some students is turned out to be a negative point too (5\%). Apparently, they lack a lecturer calling the audience to attention from time to time.

Another important negative aspect of distance teaching was that some students began to spend more time getting ready for classes $(21 \%)$.

Students note some technical issues also as negative, such as the instability of Skype communication when giving a lecture to a large audience, etc. 
Students studying at some creative specialties (choreography, vocals and instrumental performance skills) are extremely negative about distance teaching. It is quite understandable.

Lecturers also expressed their opinion about distance teaching. 55\% of lecturers are positive about distance education, and $45 \%$ are neutral. There are no people who rated in a negative way or very positive.

What are the positive aspects of distance teaching noted by the lecturers? Among those who gave a positive estimation of distance teaching, 33\% of respondents, as well as students, indicate a high structure of educational material. Also, a third of lecturers consider it to be a positive thing that students do not need to make notes of the lecture, as its text is displayed on the site. The ability to create a good presentation is rated positively by $17 \%$.

Among lecturers there are those who appreciate the opportunity to get distracted from a class $-8 \%$.

Despite the fact that there were no lecturers who had a negative attitude to distance teaching, a number of negative comments were made. Thus, $17 \%$ of respondents noted the lack of direct contact with students. As it is stated above, among students, $45 \%$ of respondents consider it to be a negative point. Obviously, direct contact with a lecturer is more important for student's psyche than for a lecturer's psyche.

Lecturers note "a sense of isolation from the team, restriction of "live" communication with colleagues and students, hypodynamia" as a negative point. This is an important remark. In the course of everyday full-time training, lecturers contact not only with students, but also with each other in their team. It turned out to be one of the most important factors of human existence in the social environment.

There is also a violation of social perception. Some lecturers formulate it in this way: "The inability to control students' perception of the material - I do not trust the answers from the other side of the screen".

There was also such a question in the questionnaire: "What level can you apply technical knowledge and techniques for working remotely up to?" The answers were distributed as follows: "I have enough knowledge, this job is a joy for me" $-10 \%$.

"I have a satisfactory level of proficiency, but this work requires a lot of effort from me" $-90 \%$. This distribution makes us conclude that at the initial stage of deep and widespread introduction of distance teaching, many lecturers face technical, methodological and psychological difficulties. This situation is not unexpected. Yu. Korbut in his investigation indicates that "a lecturer's information competence formation is just a complex process which deals with professional development of the individual and its point is the development of the individual's ability to make aware choices and responsible decisions in the field of information and communication technologies" [15].

\section{Conclusions}

The investigation of students and lecturers' attitude towards distance teaching has revealed the fact that the majority of students and lecturers have a positive attitude to the form of distance education that is currently used at our higher educational institution. At the same time, a number of problems were found out which are not only of organizational and technical character, but also of psychological one, including insufficient direct communication between lecturers and students, between students and between lecturers. Another important problem is the lack of technical and methodological training of lecturers for distance teaching, which makes lecturers spend a lot of work to get ready for lectures and practical classes. 


\section{References}

1. N. Alexandrova, Contemporary distance learning: trends, policies and good practices, 151-158 (2016)

2. T. Kolderie, T. McDonald, The Information Technology \& Innovation Foundation, 17 (2009)

3. T. Kuzmina, E. Tikhomirova, L. Goldfarb, N. Dvornikov, Student in the E-learning environment (Moscow, 2008)

4. A. Heinze, C. Procter, Journal of Information Technology Education, 5, 236-248 (2006)

5. O.I. Vaganova, I.N. Odarich, O.A.Rudakova, Level Differentiation Technology in Vocational Education, 28 42-49 (2020)

6. O.A. Rudakova, Psychological Content of Professional Training of Future Teachers, 130-145 (2018)

7. F. Luthon, B. Larroque, F. Khattar, F. Dornaika, Use of Gaming and Computer Vision to Drive Student Motivation in Remote Learning Lab Activities, 2320-2329 (2017)

8. M. Co, K.M. Chu, Distant surgical teaching during COVID-19, A pilot study on final year medical students, 24 105-109 (2020)

9. L. Huang, T. Zhang, Y. Huang, Effects of school organizational conditions on teacher professional learning in China: The mediating role of teacher self-efficacy, 66, 157161 (2020)

10. V.L. Grokholskyi, N.I. Kaida, S.V. Albul, E.V. Ryzhkov, S.Y. Trehub, Cognitive and Metacognitive Aspects of the Development of Lifelong Learning Competencies in Law Students, 8, 1-14 (2020)

11. Bura 1.V., Formation of Identity of Modern Youth in the Information Society, 244-249 (2020)

12. M. Vaquero-Dieg, P. Torrijos-Fincias, M.J. Rodriguez-Conde. Psicologia-reflexao e critica, 33, (November, 2020)

13. I.V. Bura, Theoretical Basis of Application of Methods And Methods of Meme Technology in Modern Education, 44, 106-113 (2018)

14. S.G. Abdullaev, Telecommunications and Informatization of education, 3, 85-92 (2007)

15. Yu. Korbut, Information technologies in education-2007, p. 80 (2007) 